\title{
Instability Mechanism and Key Control Technology of Deep Soft Rock Roadway under Long-Term Water Immersion
}

\author{
Wei Jing $\mathbb{D}^{1},{ }^{1,2,3,4}$ Xu Wang $\left(\mathbb{D},{ }^{2}\right.$ Pengwei Hao $\mathbb{D}^{1},{ }^{1}$ Laiwang Jing $\mathbb{D}{ }^{1}$ and Weipei Xue $\mathbb{D}^{1,2,3,4}$ \\ ${ }^{1}$ State Key Laboratory of Mining Response and Disaster Prevention and Control in Deep Coal Mines, \\ Anhui University of Science and Technology, Huainan 232001, China \\ ${ }^{2}$ School of Civil Engineering and Architecture, Anhui University of Science and Technology, Huainan 232001, China \\ ${ }^{3}$ China Coal Mine Construction Group Co., Ltd., Safety Science and Engineering Postdoctoral Research Workstation, \\ Hefei 230000, China \\ ${ }^{4}$ Anhui University of Science and Technology, Safety Science and Engineering Postdoctoral Research Mobile Station, \\ Huainan 232001, China \\ Correspondence should be addressed to Wei Jing; wjing@aust.edu.cn
}

Received 20 October 2020; Revised 18 December 2020; Accepted 28 December 2020; Published 8 January 2021

Academic Editor: Yingchun Li

Copyright ( $\odot 2021$ Wei Jing et al. This is an open access article distributed under the Creative Commons Attribution License, which permits unrestricted use, distribution, and reproduction in any medium, provided the original work is properly cited.

\begin{abstract}
More and more attention has been paid to the supporting problem of deep soft rock roadway floor with long-term water immersion in recent years. However, the existing soft rock roadway support technology rarely takes into account the influence of the immersion softening phenomenon of the roadway floor and the self-supporting structure characteristics of the surrounding rock on the stability of the surrounding rock at the same time, and the influence of the creep characteristics of rock on the deformation zone of the surrounding rock requires further research on the nature and division of the self-supporting structure of the surrounding rock. In response to the issues mentioned, based on the loading and unloading properties of the surrounding rock of the soft rock roadway, a new concept of the internal and external self-bearing structure was proposed. The fact of waterimmersed mudstone softening in the soft rock roadway floor was revealed through the field practice, and the shape of the internal and external bearing structure was determined based on the in situ monitoring results. Then, the instability mechanism of the internal and external self-bearing structure of the surrounding rock was analyzed, the position of the critical control point was calculated, and the key control technology based on the method of controlling floor heave by using double-row anchor cables to control the deformation of the roadway sides was put forward. Finally, the field industrial test showed that this support technology can effectively control the deformation and failure of soft rock roadway in the case of water immersion on the floor. This work can provide a technical reference for similar roadway support designs.
\end{abstract}

\section{Introduction}

Due to the large ground stress and low strength of surrounding rock, soft rock roadway has some engineering problems, such as difficult support, poor safety and stability, and a large amount of maintenance, which pose a great threat to coal mine safety production. The supporting technology of soft rock roadway has always been the focus of scholars. In recent years, with the gradual increase of coal mining depth, the support issue of soft rock roadway becomes more prominent, such as serious floor heave, largescale instability and failure of surrounding rock, and severe damage of the support structure, as shown in Figure 1. Although the existing support scheme has achieved certain results, due to the complex nature of the surrounding rock and the long-term existence of a large amount of free water on the floor, the problem of large deformation of the surrounding rock has not been completely resolved.

Wang et al. [1] analyzed the floor heave mechanism of high-stress soft rock roadway by using FLAC $^{3 \mathrm{D}}$ software and proposed a floor heave control scheme based on end-anchored cable bundles. Wang and Wan [2] studied the stress characteristics and failure problems of full-length FRP anchor in high-stress soft rock roadway by using FLAC ${ }^{3 \mathrm{D}}$ 


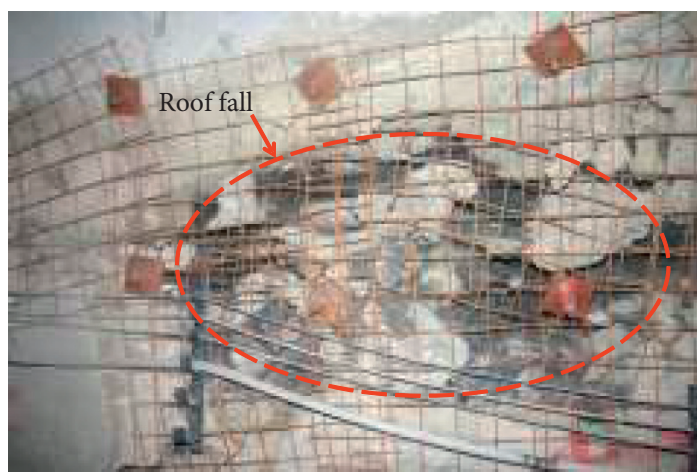

(a)

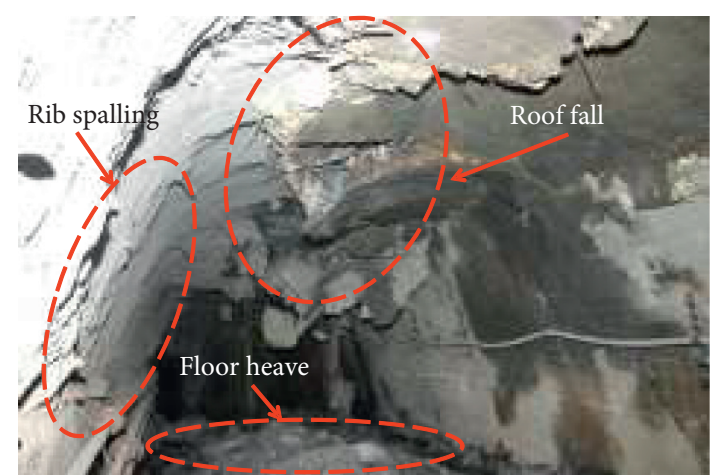

(b)

Figure 1: Deformation failure cases in the roadway. (a) Roof falling. (b) Floor heave, rib spalling, and roof falling.

software. Sun et al. [3] proposed using a flexible bearing structure composed of retractable anchor and anchor cable as the main supporting mode based on the numerical simulation results, and then grouting reinforcement was adopted to control the deformation of soft rock roadway. However, the current research objects are mainly supported structures, which do not consider the self-bearing capacity of the surrounding rock, and the situation of mudstone softening on the floor cannot be reflected during the numerical analysis [4-8], which leads to the discrepancy between the simulation results and the real situation. This means that there is still room for optimization in the support scheme.

It should be noticed that although the strength of the surrounding rock of soft rock roadway is low, the selfbearing capacity of the surrounding rock still needs to be considered in the support design so that the resulting support structure can not only meet the support requirements but also save engineering costs. This is like the stability of a bridge which is closely related to the nature of the building materials and the loads it bears, but the structure and shape of the bridge are also critical to its stability. If the structure is unreasonable, it is also difficult to guarantee stability with high-performance building materials and small loads. However, only a few scholars have studied the composition and shape of the self-bearing structure of surrounding rock. Wang et al. [9] proposed a new method to judge the anchoring effect by the double peaks of the tangential stress curve, based on the relationship between the characteristics of the self-bearing structure of the surrounding rock and the stress state of the roadway. Hou [10] researched that improving the stress state and mechanical properties of roadway surrounding rock, rationally selecting the roadway support forms, increasing support resistance, and optimizing roadway sections were effective ways to improve the control effect of deep roadway surrounding rock. Zhao et al. [11] proposed the self-bearing coefficient for evaluating the bearing capacity of surrounding rock and took the deep circular tunnel under the action of equivalent ground stress as an example to derive the formula for calculating the bearing coefficient. It is found that although some studies [12-14] take into account the self-bearing characteristics of the roadway surrounding rock when analyzing the deformation mechanism of the roadway, the deep high-stress soft rock roadway is not taken as the research object, and the important characteristic that most soft rock roadway floor mudstone will be immersed and softened is not considered, so the reference value for the research of surrounding rock control technology of high-stress soft rock roadway is limited. Kang [15] found that high confining pressure supporting can effectively improve the self-bearing capacity of surrounding rock. Tang et al. [16] proposed an optimized support scheme considering the synergistic reinforcement effect of surrounding rock, which clarified the failure mode and failure mechanism of surrounding rock in the mining roadway with high stress "three soft" coal seams. Huang and Zheng [17] revealed the interaction among the roadway roof, the two sides, and the roadway floor through numerical simulation, based on the self-stabilizing and equilibrium phenomenon in the soft rock roadway. Although the self-bearing structure of surrounding rock has been considered in some studies on surrounding rock support technology or deformation mechanism of highstress soft rock roadway, there are few studies on long-term water immersion soft rock roadway, and it is not deep and comprehensive enough [18-21]. As a result, the definition of the scope and shape of the loose zone is not accurate. Therefore, the deformation and control mechanism of soft roadway needs to be further studied, and the corresponding support technology needs to be put forward urgently.

Therefore, in order to clarify the deformation and instability mechanism of deep soft rock roadway under the condition of water immersion on the floor and determine the corresponding support scheme, the self-supporting structure of the surrounding rock was taken as the research object, and the self-supporting structure was divided according to the loading and unloading characteristics of the surrounding rock. The shape of the internal and external bearing structure was analyzed by revealing the phenomenon of water-immersed mudstone softening on the floor of the soft rock roadway. Moreover, based on the principle of mechanics, the instability mechanism of the internal and external bearing structure of surrounding rock was revealed, and the key control technology of the roadway was put forward. Finally, the field test was carried out in the 101 track roadway of Yuandian No.1 Coal Mine, and the results show that the key control technology can effectively control the 
large deformation of soft rock roadway and meet the requirements of safe and efficient production of the working face. This research can provide the scientific basis for the supporting scheme of deep high-stress soft rock roadway under the condition of floor water immersion.

\section{Characteristics of Self-Bearing Structure}

2.1. Concept and Division of Self-Bearing Structure. Due to the creep characteristics of the surrounding rock, the maximum stress value that the rock can withstand is not the peak strength previously recognized but should be the longterm strength [22]. Therefore, the deformation zoning mechanism based on the creep characteristics of surrounding rocks [22] shows that the surrounding rock of soft rock roadway should actually be divided into four deformation zones: plastic flow zone (broken zone), plastic softening zone, plastic hardening zone, and elastic zone. The four zones are the main bearers of the ground stress which bear most of the secondary ground pressure caused by roadway excavation, and the rock masses in each deformation zone influence each other in the process of bearing ground pressure. Therefore, the self-bearing structure of the roadway surrounding rock refers to the bearing unity formed by the rock mass of four deformation regions, as shown in Figure 2.

As can be seen in Figure 2, the two inner zones of the self-bearing structure are the plastic flow zone and the plastic softening zone. The former is composed of broken rocks, while the latter is composed of the rock mass whose fractures have not been fully connected. These two regions are combined to form the loose zone [23]. The distribution law of circumferential stress in Figure 2 shows that the rocks in the two regions are in the unloading stage. Although these rocks can carry, the bearing capacity is limited. The two inner zones are combined to form the internal bearing structure which is referred to as the internal structure.

Figure 2 shows that the two external zones of the selfbearing structure are the plastic hardening zone and the elastic zone, and there are no fractures in the rock mass. Because the rock mass in the plastic hardening zone is in the stable loading stage after loading (the stage after the termination of stable creep), it is in the loading stage. Furthermore, the rock mass in the elastic zone is also in the loading stage, so the two zones can be combined to form the external bearing structure of the surrounding rock, which are the main bearing parts of the ground pressure.

To sum up, the self-bearing structure can be divided into the internal structure and the external structure. The external structure is the main load-bearing structure, and the internal structure has the function of restricting the further softening, failure, and instability of the external structure.

2.2. Shape of Self-Bearing Structure. Since the cross-section shape of the roadway is definite, the inner boundary shape of the internal structure (loose zone) can be determined. The outer boundary shape of the external structure can be regarded as a mutually perpendicular square at infinity, so

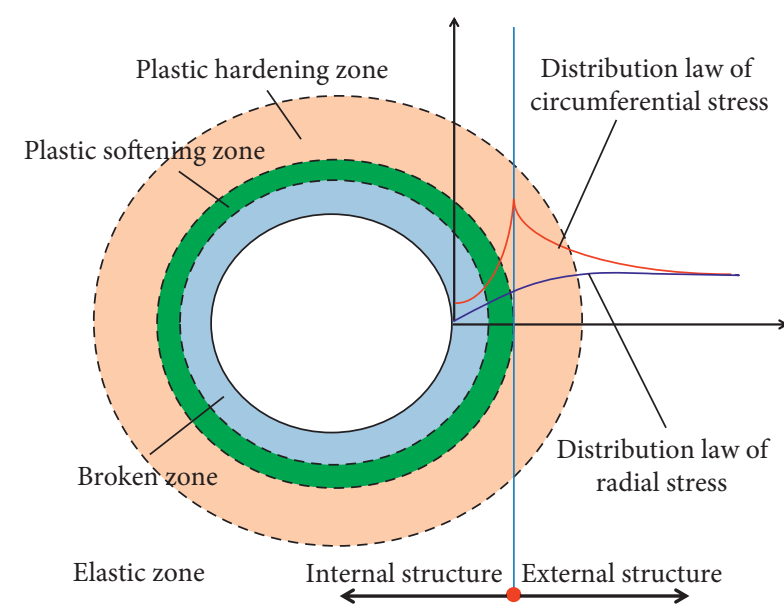

FIgURE 2: Schematic diagram of internal and external bearing structure division of surrounding rock.

the shape can be known. Therefore, the shape of the internal structure and external structure naturally depends on the outer boundary shape of the loose zone. Besides, it should be noticed that the shape of the loose zone was extremely affected by the water immersion in the roadway floor.

\subsubsection{Water Immersion and Softening of Soft Rock Roadway} Floor. Since the loose zone of the soft rock roadway floor is difficult to be tested by conventional instruments, the test range of the loose zone is limited to the side, arch, and roof, and the loose zone of the roadway floor is mainly analyzed by computer numerical calculations. However, a large amount of static or dynamic water is accumulated in the loose zone of most soft rock roadway floor in coal mines, which makes the rock properties of the floor change obviously. However, the water immersion and softening problem of the soft rock roadway floor has not been considered in the previous numerical analysis, and the actual shape of the roadway loose zone obviously deviated from the numerical analysis result so that the actual situation of the project cannot be reflected accurately.

According to the basic principle of aerodynamics, the roadway floor anchor cable drilling rig developed by Anhui University of Science and Technology can realize rapid drilling on the roadway floor. This equipment is small in size and easy to operate, and it can quickly monitor the range of the loose zone of the soft rock roadway floor, as shown in Figure 3.

The roadway floor anchor cable drilling rig has been used in hundreds of coal mines in China since 2010, such as Guqiao Coal Mine, Zhuji Coal Mine, Panyidong Coal Mine, Panbei Coal Mine, Yangzhuang Coal Mine, Xutuang Coal Mine, Xinghu Coal Mine, Luling Coal Mine, and Zouzhuang Coal Mine. In the course of use, it is found that a large amount of water will be gushed out in the process of floor drilling. When drilling a vertical hole with a diameter of $75 \mathrm{~mm}$ and a depth of about $8 \mathrm{~m}$, the average water inflow is about 1.8 tons. In general, when the borehole is drilled to $300 \mathrm{~mm}-700 \mathrm{~mm}$ below the floor, the water will start to flow until the drilling is stopped, and when the drill pipe is pulled 


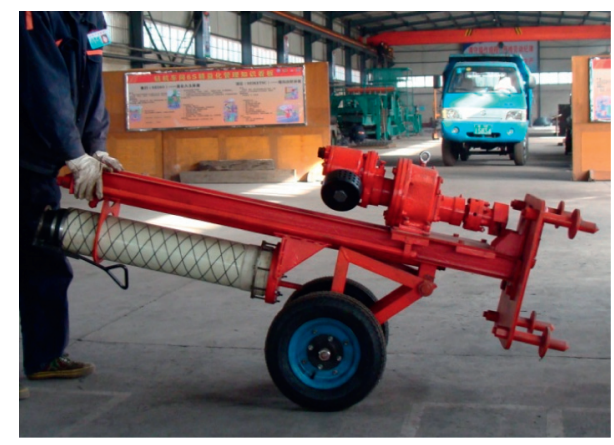

Figure 3: Roadway floor anchor cable drilling rig.

out, the hole is immediately filled with water. It can be seen that a large amount of free water is accumulated in the loose zone of the roadway floor, and there are four main sources of floor water: construction water produced by roadway excavation, infiltration of water from ditches, gradual infiltration of static water from rock strata, and inflow of water conservancy channels in a loose circle of interconnected roadway floor.

Due to the softening coefficient of major rocks [24], all water-immersed rocks have the property of softening, but the softening degree of soft rock is much greater than that of hard rock. The softening coefficient of water-immersed mudstone commonly used in coal mines is very close to the lower limit of the softening coefficient of clay rock, and the strength of clay rock after immersion softening can be reduced to as low as $8 \%$ of the original strength. Thus, it can be inferred that in the condition of long-term water immersion, the soft rock in the range of floor loose zone will continue to soften and destroy due to the decrease in strength, and the range of loose zone will continue to expand. As a result, the final stable shape is obviously different from the previous numerical simulation results. Therefore, it is necessary to analyze the internal and external structure shape of the soft rock roadway when the floor is immersed in water.

2.2.2. Shape of External Structure. Compared with the external structure, the internal structure is equivalent to a supporting structure, and the supporting carrier of roadway surrounding rock after removing the supporting structure is the external structure, as shown in Figure 4(a). It can be seen from Figure 4 that the external structure can be treated as an approximate elastic body, and the shape and size of the inner boundary of the external structure depend on the scope of the internal structure (loose zone).

2.2.3. Shape of Internal Structure. The internal structure of the surrounding rock is the loose zone, which plays a supporting role in the external structure. Because the shape of the internal structure of the roadway floor under water immersion and softening cannot be determined by numerical simulation, the on-site monitoring data of the 101 track roadway in Yuandian No.1 Coal Mine of Huaibei Mining Co., Ltd., is used to reveal the actual situation of the loose zone of soft rock roadway.
The loose zone was detected by the comprehensive detection method of drilling core, ultrasonic testing, and peephole observation. The ultrasonic tester cannot be used for the arch and roof of the roadway due to the development of rock cracks, so the borescope was used to detect these regions. The sides of the roadway were also detected by the borescope and then rechecked after grouting for 24 hours by the BA-II ultrasonic rock fracture detector. At the bottom corners of the roadway, the ultrasonic detectors were used to check after grouting for 24 hours. In addition, the roadway floor anchor cable drilling rig was used to determine the range of the loose zone by observing the termination interface of cement slurry penetration. The test pieces of equipment are shown in Figures 3 and 5.

The test results of five positions in the loose zone are shown in Figure 6. The height of the loose zone at the top is $1690 \mathrm{~mm}$, the depth of the loose zone at the middle of the floor is $4990 \mathrm{~mm}$, the depth of the loose zone at the bottom corner ( $45^{\circ}$ from horizontal) is $2720 \mathrm{~mm}$, the scope of the loose zone at the arch waist is $2320 \mathrm{~mm}$, and the width at the positions of $1000 \mathrm{~mm}$ above the floor on the sides is $2010 \mathrm{~mm}$. According to the size of each part of the loose zone, the loose zone shape of the 101 track roadway can be obtained by connecting the test results with a smooth curve. From Figure 6, it can be obtained that the longitudinal size of the outer boundary of the loose zone $(11.08 \mathrm{~m})$ is much larger than the transverse size $(8.82 \mathrm{~m})$, and it is an approximate vertical ellipse.

At this point, the shape and size of the outer boundary of the loose zone have been determined. Since the shape and size of the roadway section are known, the shape and range of the internal structure and the external structure (the loose zone) of the surrounding rock can be determined, as shown in Figure 3.

\section{Instability Mechanism of Internal and External Bearing Structures}

\subsection{Instability Mechanism of External Structure.} Considering the water immersion and softening of the loose zone of the roadway floor, the outer boundary sharp of the loose zone is approximately a vertical ellipse, and the shape of the roadway is not the circle assumed in many previous studies [25-27]. Therefore, it is very difficult to reveal the stress distribution law of the surrounding rock in each deformation zone. To obtain the supporting technology applicable to high-stress soft rock roadway under the condition of long-term water immersion on the floor, the external structure can be regarded as a combination of several approximately vertical elliptic rings with equal thickness based on the knowledge of solid mechanics [28], as shown in Figure $7(\mathrm{a})$.

First of all, because the deformation and failure of the roadway start from the inner layer, only the stress of the innermost layer of the external structure (at the outer boundary of the loose zone) is analyzed here. Since the pressure acting on the outside of the ring is greater than the support force from the loose zone acting on the inside of the ring, in order to clearly reflect the force acting on the ring, 


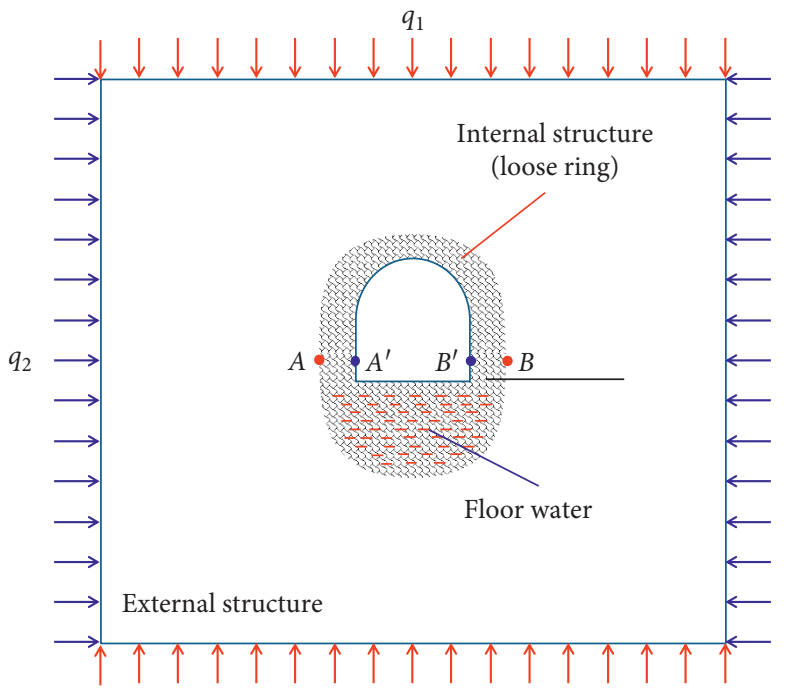

(a)

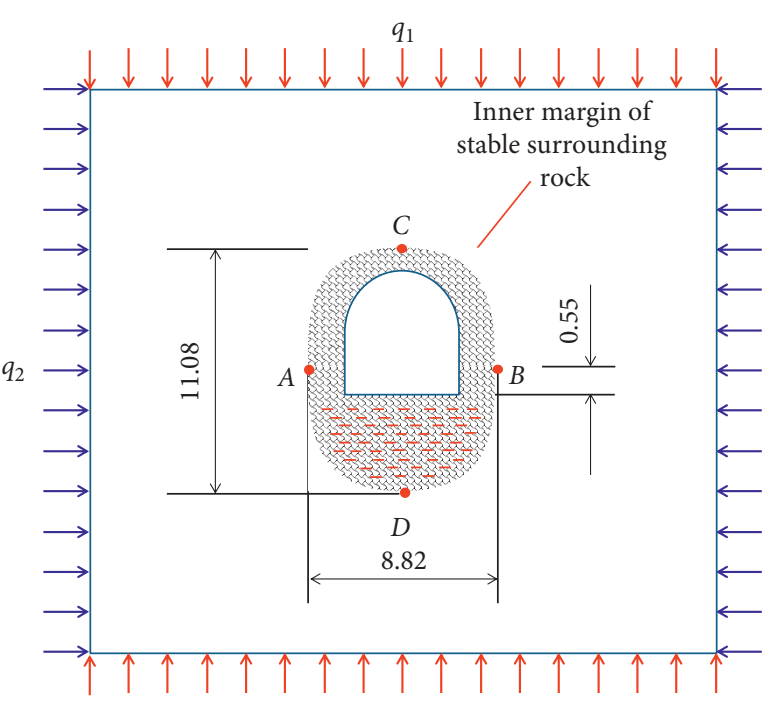

(b)

FIGURE 4: Stress analysis of the bearing structure in soft rock roadway (unit: m).

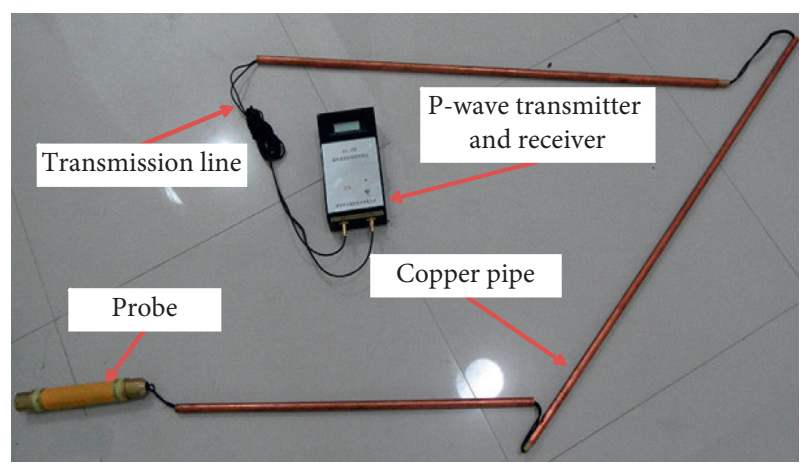

FigURE 5: BA-II ultrasonic rock fracture detector.

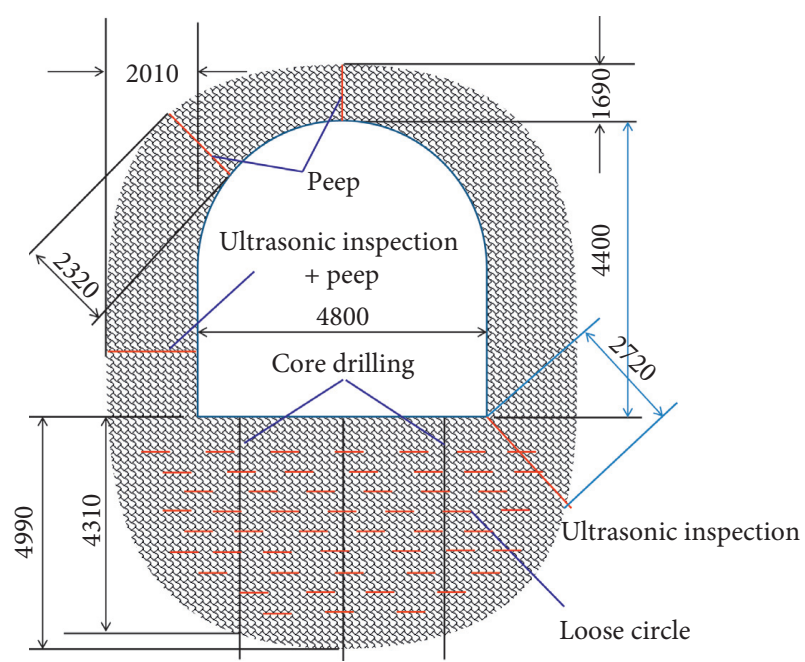

FIGURE 6: Detection scheme of the broken rock zone in 101 track roadway of Yuandian No.1 coal mine (unit: $\mathrm{mm}$ ).

the pressure state of the ring is expressed by the pressure difference between the inside and outside of the ring, where $q_{3}$ represents the pressure difference of the arched portion of the vertical elliptical ring, and $q_{4}$ represents the pressure difference of the near-vertical parts of the vertical elliptical ring, as shown in Figure 7(b). The vertical elliptical ring can be hypothetically cut open at the position of the upper and lower arch foundation to obtain four independent parts, which are two near-vertical parts and two arch parts described in Figure 7(c). According to the mechanics' principle, the main stress on the cross sections of the upper and lower arch parts of the ring is compressive stress, so the tensile stress is difficult to occur in the ring, and the bending moment on the cross section of the ring is very small, which results in strong bearing capacity and high stability of the ring.

The stress condition of the left and right near-vertical parts is quite different from that of the upper and lower arch parts. There are two main sources of normal stress on the cross section: one is the compressive stress transmitted from the upper and lower arch parts, and the other one is the bending normal stress produced by the lateral pressure difference $q_{4}$. Because the latter will produce a large bending moment on the cross section, this means a large bending normal stress (tensile stress) will be generated on the cross section. Therefore, the deformation and failure of soft rock roadway under the combined action of two stresses can be divided into two situations. One case is that when there is tensile stress on the cross section of the near-vertical parts if the tensile stress reaches or exceeds the strength limit, the strength failure must first occur at a certain point on the part. Even if the strength limit is not reached, when the long-term strength is exceeded, unstable creep will also occur and eventually lead to failure. The other case is that if the nearvertical parts are regarded as a bar member fixed at both ends, the bar member will be unstable when the pressure from the upper and lower arch part exceeds the critical pressure. Thus, it can be seen that when the vertical pressure is too large, the near-vertical parts will be unstable. However, when the horizontal pressure is too large, the strength failure 


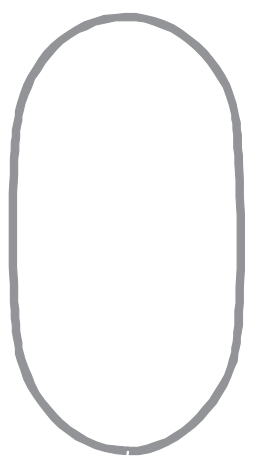

(a)

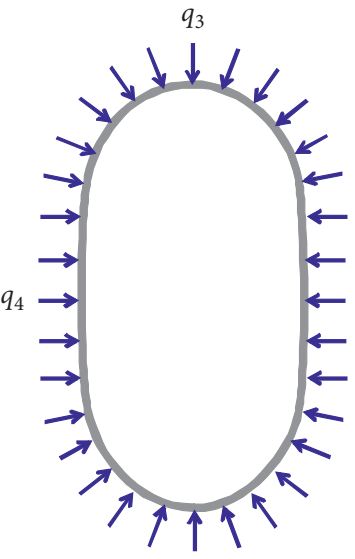

(b)
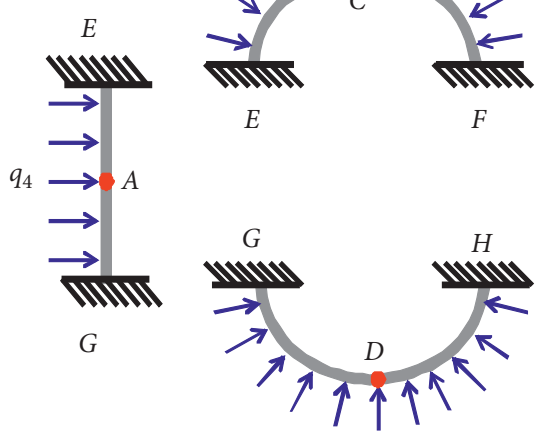

(c)

FIGURE 7: Instability mechanism analysis of the peripheral bearing structure.

of the near-vertical parts will occur. It means that lateral horizontal pressure and vertical pressure will lead to the failure of the near-vertical parts of the elliptic ring. Therefore, finding out the earliest failure points of the left and right near-vertical parts is the key to reveal the instability mechanism of the external structure of the surrounding rock, and it is also the basis to study the key control technology of soft rock roadway.

As can be seen in Figure 7(c), because the loaded bodies on the left and right sides are approximately linear, and the whole external structure can be regarded as approximate elastic bodies, the relevant theory of structural mechanics can be applied to analyze the two parts approximately as two statically indeterminate beams $E G$ and $F H$ fixed at both ends. The $E G$ beam is taken as an example for a specific calculation, as shown in Figure 8(a). Based on the basic theory of structural mechanics and elasticity, the lateral horizontal pressure difference $q_{4}$ acting on the EG beam is approximately uniformly distributed.
According to the principle of force method in structural mechanics, the typical equation of force method for a statically indeterminate beam with $n$ degree is as follows:

$$
\left\{\begin{array}{l}
\delta_{11} X_{1}+\delta_{12} X_{2}+\cdots+\delta_{1 i} X_{i}+\delta_{1 n} X_{n}+\Delta_{1 P}=0 \\
\cdots \cdots \cdots \cdots \\
\delta_{i 1} X_{1}+\delta_{i 2} X_{2}+\cdots+\delta_{i i} X_{i}+\delta_{i n} X_{n}+\Delta_{i P}=0 \\
\cdots \cdots \cdots \cdots \\
\delta_{n 1} X_{1}+\delta_{n 2} X_{2}+\cdots+\delta_{n i} X_{i}+\delta_{n n} X_{n}+\Delta_{n P}=0
\end{array}\right.
$$

When calculating the statically indeterminate beam by force method [29], the influence of shear force and axial force on the displacement is usually ignored, and only the influence of bending moment is considered, so the calculation formula of each coefficient in the typical equation of force method is as follows:

$$
\begin{aligned}
\delta_{i i} & =\sum \int \frac{\bar{M}_{i}^{2} \mathrm{~d} s}{E I}+\sum \int \frac{\bar{F}_{N i}^{2} \mathrm{~d} s}{E A}+\sum \int k \frac{\bar{F}_{S i}^{2} \mathrm{~d} s}{E A}=\sum \int \frac{\bar{M}_{i}^{2} \mathrm{~d} s}{E I}, \\
\delta_{i j} & =\delta_{j i}=\sum \int \frac{\bar{M}_{i} \cdot \bar{M}_{i} \mathrm{~d} s}{E I}+\sum \int \frac{\bar{F}_{N i} \cdot \bar{F}_{N j} \mathrm{~d} s}{E A}+\sum \int k \frac{\bar{F}_{S i} \cdot \bar{F}_{S j} \mathrm{~d} s}{E A}=\sum \int \frac{\bar{M}_{i} \cdot \bar{M}_{j} \mathrm{~d} s}{E I}, \\
\Delta_{i P} & =\sum \int \frac{\bar{M}_{i} \cdot \bar{M}_{P} \mathrm{~d} s}{E I}+\sum \int \frac{\bar{F}_{N i} \cdot \bar{F}_{N P} \mathrm{~d} s}{E A}+\sum \int k \frac{\bar{F}_{S i} \cdot \bar{F}_{S P} \mathrm{~d} s}{E A}=\sum \int \frac{\bar{M}_{i} \cdot \bar{M}_{P} \mathrm{~d} s}{E I} .
\end{aligned}
$$

The above coefficients can be calculated by using the graph multiplication method [29], where the flexibility coefficient $\delta_{i j}$ represents the displacement of the action point of $X_{i}$ in the basic system along the $X_{i}$ direction under the action of the unit unknown force $X_{j}=1$. The free term $\Delta_{i \mathrm{P}}$ represents the displacement of the action point of $X_{i}$ in the basic system along the $X_{i}$ direction under external load. Finally, the bending moment of the statically indeterminate structure can be calculated by the superposition method principle, and the superposition equation is expressed as follows:

$$
M=\bar{M}_{1} X_{1}+\bar{M}_{2} X_{2}+\cdots+\bar{M}_{n} X_{n}+M_{P}=0 .
$$

The beam EG is a statically indeterminate structure with three degrees, so it can be calculated by the force method, as shown in Figures 8(b)-8(f). Let the length of the $E G$ beam be 


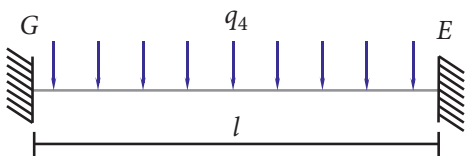

(a)

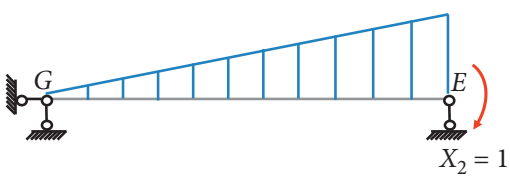

(d)

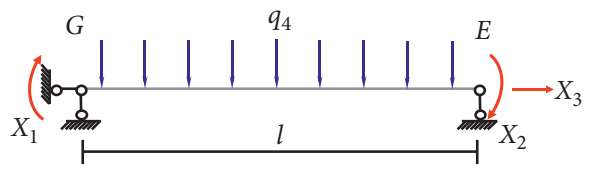

(b)

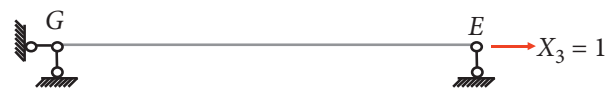

(e)

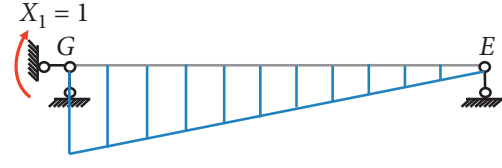

(c)

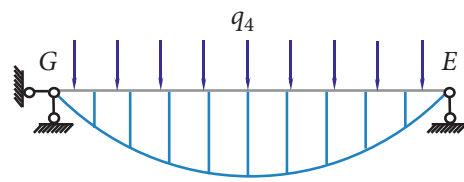

(f)

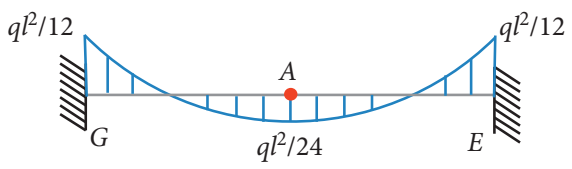

(g)

Figure 8: Stress analysis of statically indeterminate structure $E G$ under uniformly distributed load. (a) Original structure. (b) Basic system. (c) Bending moment diagram $\overline{M_{1}}$. (d) Bending moment diagram $\overline{M_{2}}$. (e) Bending moment diagram $\overline{M_{3}}$. (f) Bending moment diagram $M_{P}$. (g) Final bending moment diagram $M$.

$l, \overline{X_{1}}, \overline{X_{2}}$, and $\overline{X_{3}}$ are the forces instead of the removed superfluous constraints described in Figure $8(\mathrm{~b})$, graphs $\overline{M_{1}}$, $\overline{M_{2}}$, and $\overline{M_{3}}$ are the bending moment diagrams obtained from the unit forces $\overline{X_{1}}, \overline{X_{2}}$, and $\overline{X_{3}}$ acting on the basic structure, respectively, and graph $M_{P}$ shows the bending moment obtained by the original external load acting alone on the basic structure, as shown in Figures 8(c)-8(f).

First of all, the equation of the force method can be established, as shown in the following formula:

$$
\left\{\begin{array}{l}
\delta_{11} X_{1}+\delta_{12} X_{2}+\delta_{13} X_{3}+\Delta_{1 P}=0 \\
\delta_{21} X_{1}+\delta_{22} X_{2}+\delta_{23} X_{3}+\Delta_{2 P}=0 \\
\delta_{31} X_{1}+\delta_{32} X_{2}+\delta_{33} X_{3}+\Delta_{3 P}=0
\end{array}\right.
$$

The coefficients $\delta_{i j}$ and free term $\Delta_{i P}$ in equation (4) can be calculated by using the following formulas, respectively:

$$
\begin{aligned}
& \delta_{11}=\sum \int \frac{\bar{M}_{1}^{2} \mathrm{~d} s}{E I}=\frac{l}{3 E I}, \\
& \delta_{22}=\sum \int \frac{\bar{M}_{2}^{2} \mathrm{~d} s}{E I}=\frac{l}{3 E I}, \\
& \delta_{33}=\sum \int \frac{\bar{M}_{3}^{2} \mathrm{~d} s}{E I}+\sum \int \frac{\bar{N}_{3}^{2}}{E A} \mathrm{~d} s=\frac{l}{E A}, \\
& \delta_{12}=\delta_{21}=\sum \int \frac{\overline{M_{1}} \cdot \overline{M_{2}} \mathrm{~d} s}{E I}=-\frac{l}{6 E I}, \\
& \delta_{13}=\delta_{31}=\sum \int \frac{\bar{M}_{1} \cdot \bar{M}_{3} \mathrm{~d} s}{E I}+\sum \int \frac{\bar{N}_{1} \cdot \bar{N}_{3}}{E A} \mathrm{~d} s=0, \\
& \delta_{23}=\delta_{32}=\sum \int \frac{\bar{M}_{2} \cdot \bar{M}_{3} \mathrm{~d} s}{E I}=0,
\end{aligned}
$$

$$
\begin{aligned}
& \Delta_{1 P}=\sum \int \frac{\bar{M}_{1} \cdot M_{P} \mathrm{~d} s}{E I}=\frac{q l^{3}}{24 E I}, \\
& \Delta_{2 P}=\sum \int \frac{\bar{M}_{2} \cdot M_{P} \mathrm{~d} s}{E I}=-\frac{q l^{3}}{24 E I}, \\
& \Delta_{3 P}=\sum \int \frac{\bar{M}_{3} \cdot M_{P} \mathrm{~d} s}{E I}+\sum \int \frac{\bar{N}_{3} \cdot N_{P} \mathrm{~d} s}{E A}=0 .
\end{aligned}
$$

By substituting formulas (5)-(13) into formula (4), $X_{1}$, $X_{2}$, and $X_{3}$ can be calculated as follows:

$$
\begin{aligned}
& X_{1}=-\frac{q l^{2}}{12}, \\
& X_{2}=\frac{q l^{2}}{12}, \\
& X_{3}=0 .
\end{aligned}
$$

Finally, the bending moment diagram of the statically indeterminate beam $E G$ can be drawn from the superposition formula (15), as shown in Figure 8(g).

$$
M=\overline{M_{1}} X_{1}+\overline{M_{2}} X_{2}+\overline{M_{3}} X_{3}+M_{P} .
$$

From the calculation results, it can be seen that when $q_{4}$ is uniformly distributed load, the maximum bending moment of the statically indeterminate beam appears at the midpoint, which means that the maximum deformation positions of the near-vertical parts $E G$ and $F H$ at the inner boundary of the external structure are midpoints $A$ and $B$, as shown in Figures $7(\mathrm{c})$ and $8(\mathrm{~g})$.

In summary, points $A$ and $B$ in Figure 6 are the locations where the external structure is most prone to deformation and failure. According to the mechanics' principle, if an outward force is applied at each of the two locations, the 
stability and bearing strength of the surrounding rock in the external structure will be greatly improved.

3.2. Instability Mechanism of the Internal Structure. Due to the long-term water immersion and softening of the loose zone in the roadway floor, the rock mechanical properties of the loose zone above the floor are quite different from those of the water-immersed floor, and the bearing capacity of the latter is much less than that of the former. Therefore, the bearing capacity of the whole internal structure depends on that of the water-immersed loose zone on the floor, which is called the cask effect.

When the external force acting on the whole loose zone is less than a certain limit, the deformation of the waterimmersed loose zone on the floor is within the range of stable creep, and the whole structure is stable. However, when the external force acting on the loose zone is greater than or equal to the above limit, the unstable creep deformation of the water-immersed loose ring will begin to occur, and the stability of the loose zone will be reduced.

The decrease of structural stability of the loose zone directly leads to the weakening of its supporting force to the external surrounding rock, which makes the external surrounding rock continue to move to the inside of the roadway. In the process of the displacement, the rock mass of the floor loose zone will deform as a whole, and the deformation direction can only be upward, so the floor heave must occur on the roadway floor. Moreover, it is bound to cause the loose zone in lower parts of the roadway sides to move inward. In this way, the supporting ability of the loose zone to external rock mass will gradually weaken from the bottom up, and the deformation of the external rock mass will also gradually increase from the bottom up. Ultimately, it can lead to serious deformation and failure of the surrounding rock and loss of safety. Therefore, the critical control points and control technology of soft rock roadway are studied based on the above internal and external structure instability mechanism in the following.

\section{Critical Control Points and Control Technology}

4.1. Critical Control Points of the External Structure. The shape of the external structure has been shown in Figure 6 and is based on the elastic theory and the study of the instability mechanism of the external structure mentioned above. Points $A$ and $B$ are the locations at the inner boundary of the external structure which is most prone to loss of stability and strength failure, which means they are the critical control points of the surrounding rock at the inner boundary of the external structure. According to the stability theory, the effective way to enhance the stability of the external structure is to set a horizontal outward force at $A$ and $B$ or to set two or more symmetrical horizontal outward forces along the vertical direction with $A$ and $B$ as symmetry points. Moreover, according to the strength theory, the same method is used to improve the bearing capacity of the external structures.
4.2. Critical Control Points of the Internal Structure. The loose zone is attached to the external structure because of the bolt, and it bears the extrusion effect of the external structure because of its own bearing capacity at the same time. Since the length of the bolt is difficult to control the stability and bearing capacity of the external structure, the maximum radial deformation position of external structure is still at points $A$ and $B$. Therefore, the loose zone is bound to be squeezed by the external structure at the corresponding position, which leads to the inward displacement of the loose zone in the lower parts of the roadway sides. It can be concluded that the critical control points in the loose zone must be the points $A^{\prime}$ and $B^{\prime}$ corresponding to points $A$ and $B$ in Figure 6(a). Since points $A, B, A^{\prime}$, and $B^{\prime}$ are on the same horizontal line, the critical control points of the internal and external structure are in the same horizontal position.

4.3. Key Control Technology. The above analysis shows that the first deformation of the loose zone starts from the horizontal inward movement at points $A$ and $B$ on the inner boundary of the external structure. Figure 7 (c) shows that the simplest and scientific way to control the strength, stiffness, and stability of the parts $E G$ and $F H$ at the outer boundary of the loose zone is to apply one or a group of horizontal forces on the inside, as shown in Figure 9.

In general, when the lateral pressure difference $q_{4}$ acting on the EG part is small, the technique shown in Figure 9(a) can be used to set a horizontal anchor cable at point $A$. When the lateral pressure difference $q 4$ is large and the span length of the EG part is long, the technology to set two horizontal anchor cables vertically at the two positions $Q$ and $T$ with $A$ as the symmetry point shown in Figure 9(b) can be used, which can better improve the strength, stiffness, and stability of the roadway surrounding rock, and restrain the deformation of the roadway floor heave. Therefore, the key control technology of the soft rock roadway is the method of controlling floor heave by using double-row anchor cables to control the deformation of the roadway sides, as shown in Figure 10.

\section{Field Industrial Test}

The surrounding rock control mechanism and key control technology of soft rock roadway mentioned above have been successfully applied in Zhuji Coal Mine, Yangzhuang Coal Mine, Zouzhuang Coal Mine, Yuandian No.1 Coal Mine, and other coal mines in Huainan-Huaibei areas, and remarkable support results have been obtained. This section takes the 101 track roadway of the Yuandian No.1 Coal Mine as an example.

5.1. Engineering Geology of 101 Track Roadway. The 101 track roadway of Yuandian No.1 Coal Mine is located on the roof of No.10 coal at a depth of 740 meters. It is arranged in the argillaceous sandstone layer along the rock strike, and there is large tectonic stress in the rock layer. The maximum principal stress is $20.91 \mathrm{MPa}$ with an azimuth angle of $86.39^{\circ}$, which is approximately perpendicular to the roadway strike, 


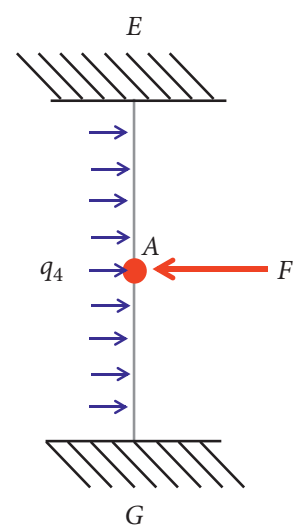

(a)

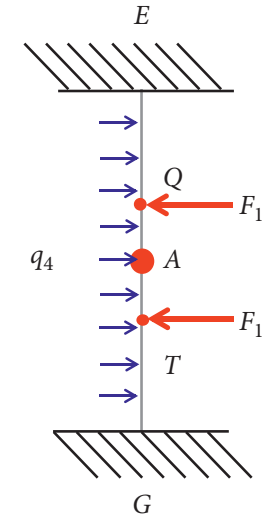

(b)
FIgURE 9: Schematic diagram of key control technology.

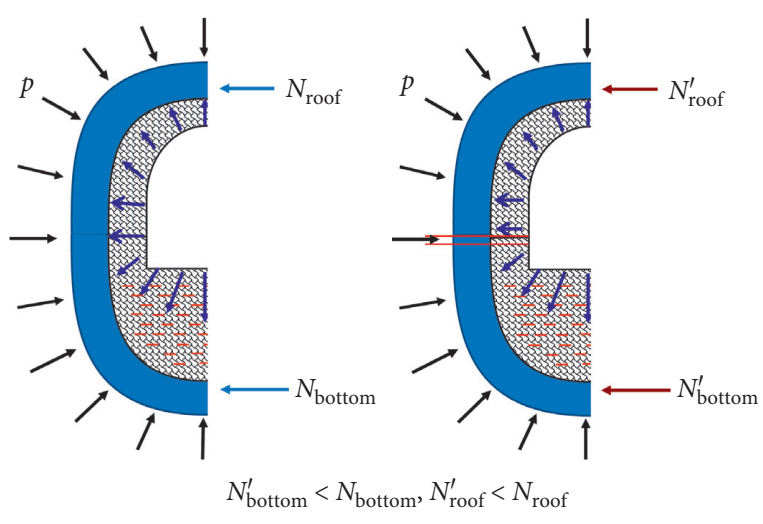

Figure 10: Schematic diagram of double-row anchor cables reinforcement support scheme.

and the minimum principal stress is $9.91 \mathrm{MPa}$ with an azimuth angle of $173.98^{\circ}$, and the lateral pressure coefficient is approximately 1.50 . In addition, the mining of No. 1011 working surface also makes the adjacent 101 track roadway deeply affected by the mining stress. Due to the large tectonic stress and the mining of No. 1011 working face, the deformation of 101 track roadway is more serious. The distribution of rock strata in the 101 track roadway is shown in Figure 11.

5.2. Original Supporting Scheme of 101 Track Roadway. The 101 track roadway is a semicircular arch roadway with a height of $4400 \mathrm{~mm}$, a width of $4800 \mathrm{~mm}$, and a section area of $18.6 \mathrm{~m}^{2}$. The original supporting scheme is bolting and shotcreting with wire mesh, the specification of the bolts is $\Phi 20 \times 2400 \mathrm{~mm}$, the spacing is $700 \mathrm{~mm} \times 700 \mathrm{~mm}$, and the thickness of the C20 concrete spray layer is $150 \mathrm{~mm}$. The "anchor cable $+M$ steel belt" reinforcement support is adopted above the arch baseline of the roadway. The parameters of the anchor cables are $\Phi 17.3 \times 6300 \mathrm{~mm}$, the spacing is $1500 \mathrm{~mm} \times 1500 \mathrm{~mm}$, and the specification of steel belt is $M 3400 \times 180 \times 4 \mathrm{~mm}$. Five rows of anchor cables and $M$ steel belts are arranged from the middle top to the two sides along the strike direction of the roadway, as shown in Figure 12.

Comparing the original supporting scheme with Figure 11 , it is clear that there is a lack of effective support at the critical control points of the internal and external structure of surrounding rock, which is the reason for the continuous deformation of the roadway in the high ground stress field.

5.3. Optimized Support Scheme. According to the instability mechanism and key control technology of the internal and external bearing structure of the soft rock roadway described in this paper, the distance from the key control points $A$ or $B$ to the roadway floor is $0.55 \mathrm{~m}$, which can be calculated from the dimensions of the 101 track roadway in Figure 6 . Therefore, two horizontal outward forces should be set vertically with $A$ and $B$ as symmetrical points. The position of the lower anchor cable is set at $300 \mathrm{~mm}$ above the floor (if the distance is less than $300 \mathrm{~mm}$, the construction difficulty of the anchor cable will be greatly increased), and the position of the upper anchor cable is set at the $1100 \mathrm{~mm}$ above the floor. In other words, the optimized support scheme is to set up two rows of anchor cables at $300 \mathrm{~mm}$ and $1100 \mathrm{~mm}$ above the roadway floor, and the specific parameters are shown in Figure 13.

5.4. Analysis of Monitoring Results. In order to verify the correctness of the theory and technology, the researchers arranged to measure stations in the 101 track roadway and compared the monitoring data of approaching velocity of the two sides and floor heave velocity before and after the implementation of the optimization scheme. The on-site layout of the observation section and the measuring points in the sections are shown in Figure 14.

This monitoring uses the JSS30A digital display roadway section convergence instrument shown in Figure 15 to record the displacement change of the roadway surface. In this monitoring, the JSS30A digital display roadway section convergence meter shown in Figure 15 was used to record the displacement change of the roadway surface. The measurement accuracy of the instrument is $0.06 \mathrm{~mm}$, and the resolution is $0.01 \mathrm{~mm}$. In actual use, it was found that the accuracy of the instrument can reach $0.02 \mathrm{~mm}$. In the observation section, the deformation of the roadway sides is monitored by the distance change between the two measuring points 1 and 2 arranged on the waistline, and the deformation of the roadway floor is monitored by the distance change from the middle point 3 of the roadway floor to the measuring point 4 at $400 \mathrm{~mm}$ above the waistline. The comparison of the monitoring results is shown in Figure 16.

From Figure 16, it can be seen that the deformation speed of roadway sides and floor heave has not slowed down obviously during the implementation of the original support scheme, which shows that the surrounding rock deformation has not been well controlled. After using the improved scheme to reinforce the roadway sides with anchor cables for about 100 days, the deformation speed of the roadway sides decreased from $0.36 \mathrm{~mm} /$ days to $0.07 \mathrm{~mm} /$ days with a 


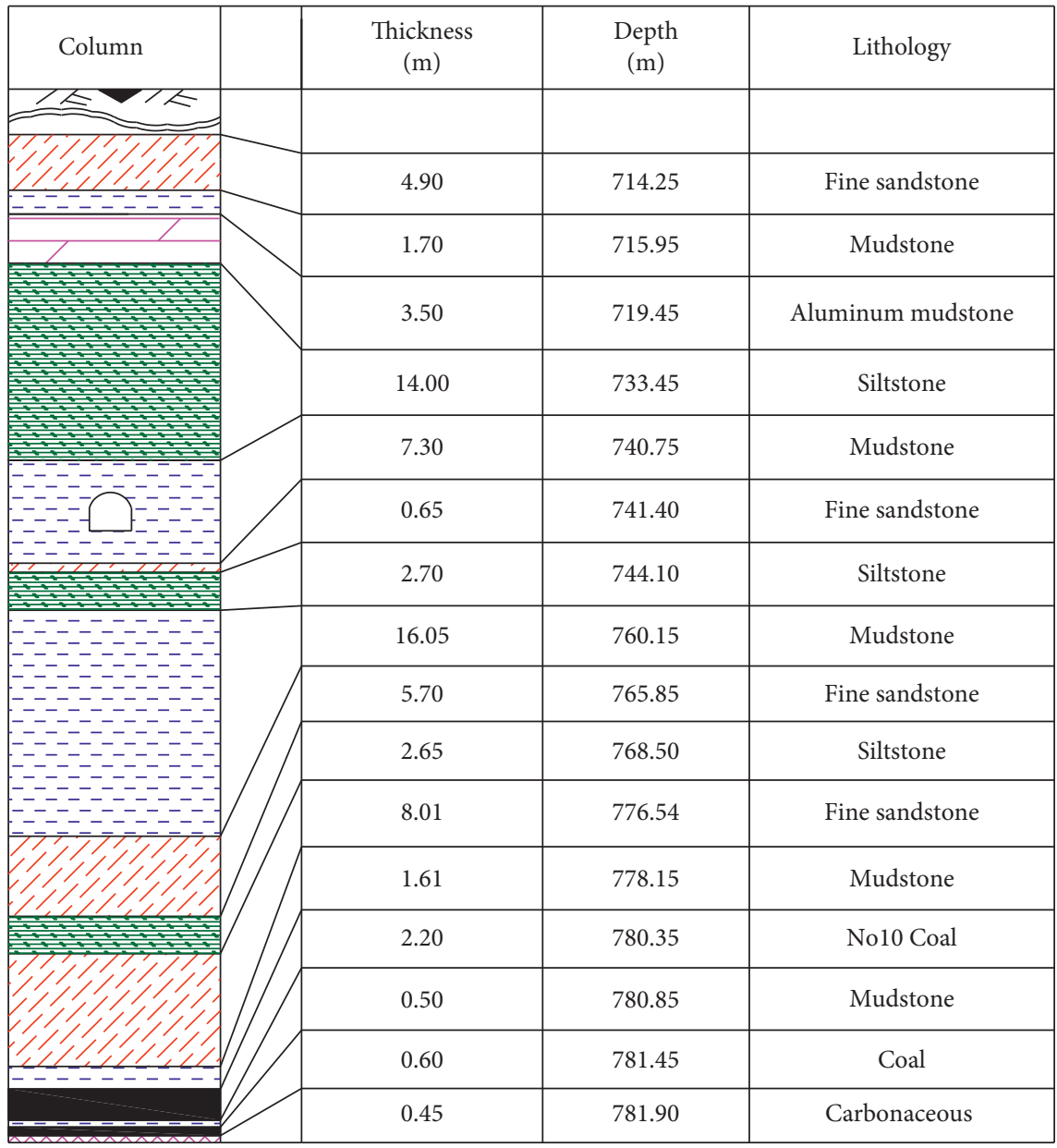

FIGURE 11: Sketch of stratigraphic columns in 101 track roadway.

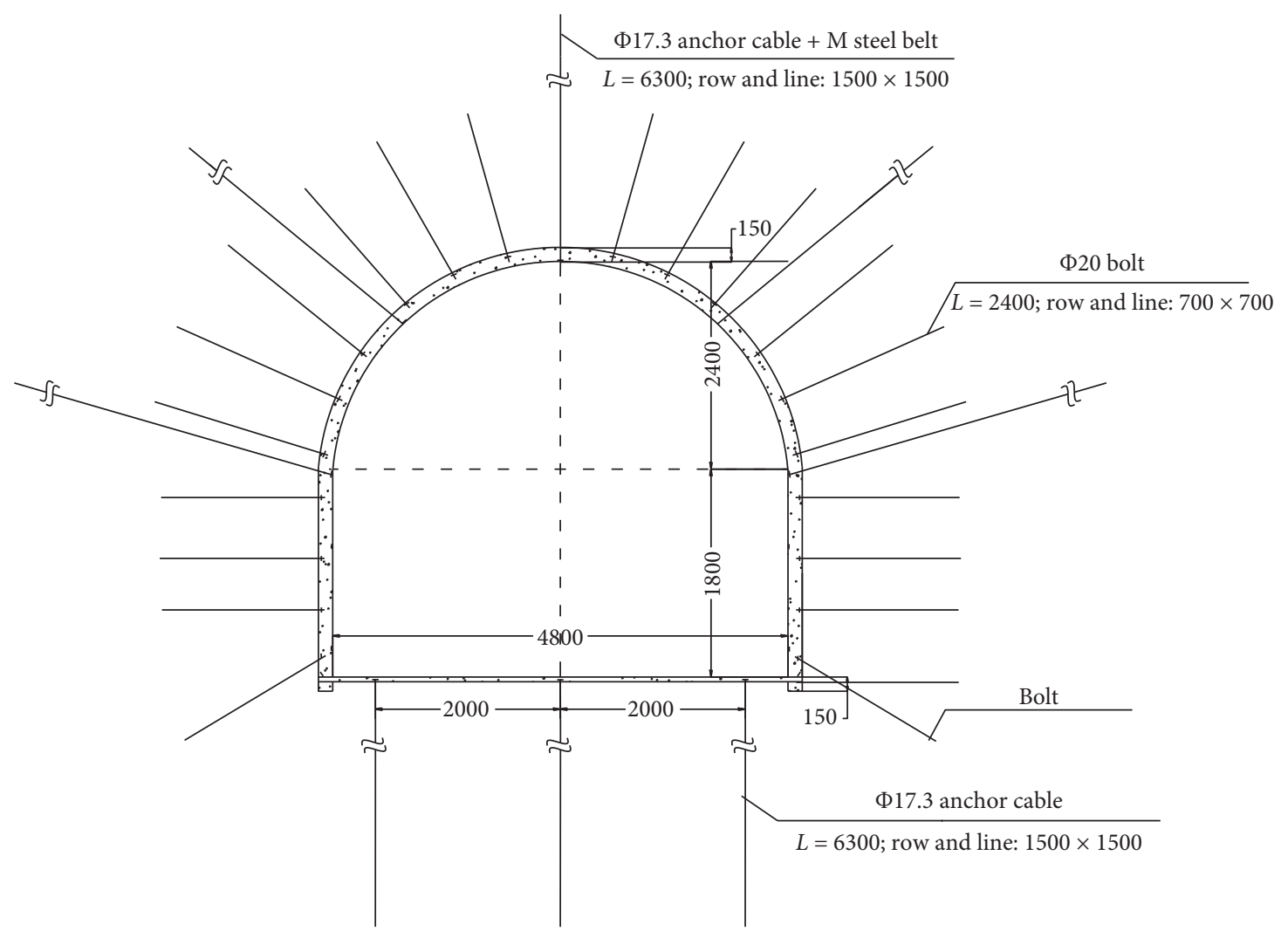

FIgURE 12: Original supporting scheme of 101 track roadway (unit: $\mathrm{mm}$ ). 


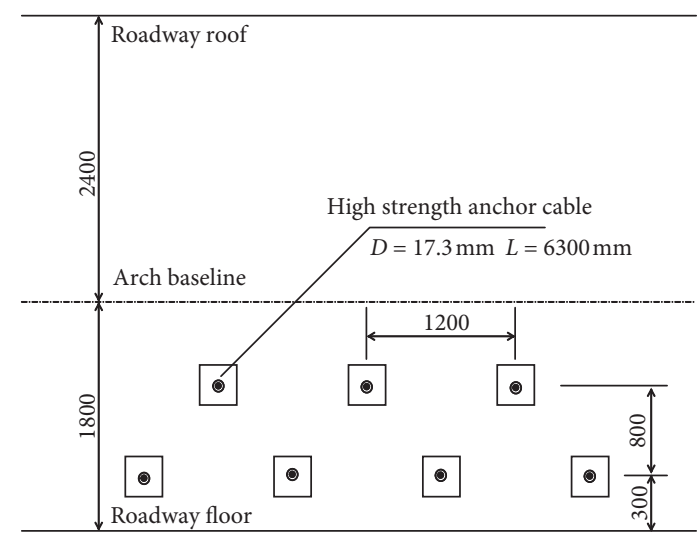

(a)

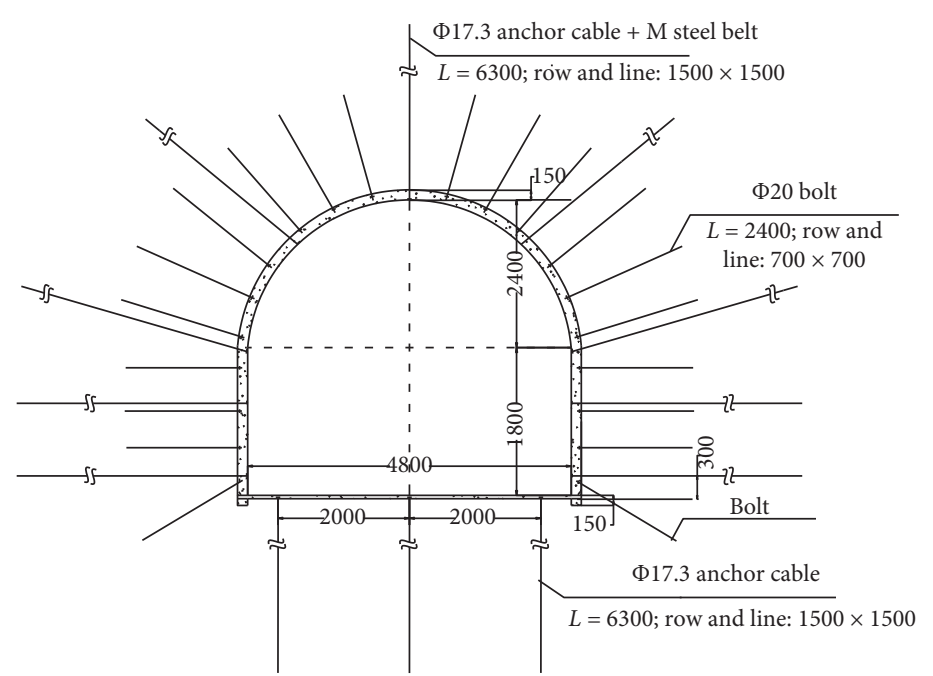

(b)

FIGURE 13: Reinforcement supporting scheme of 101 track roadway (unit: mm).

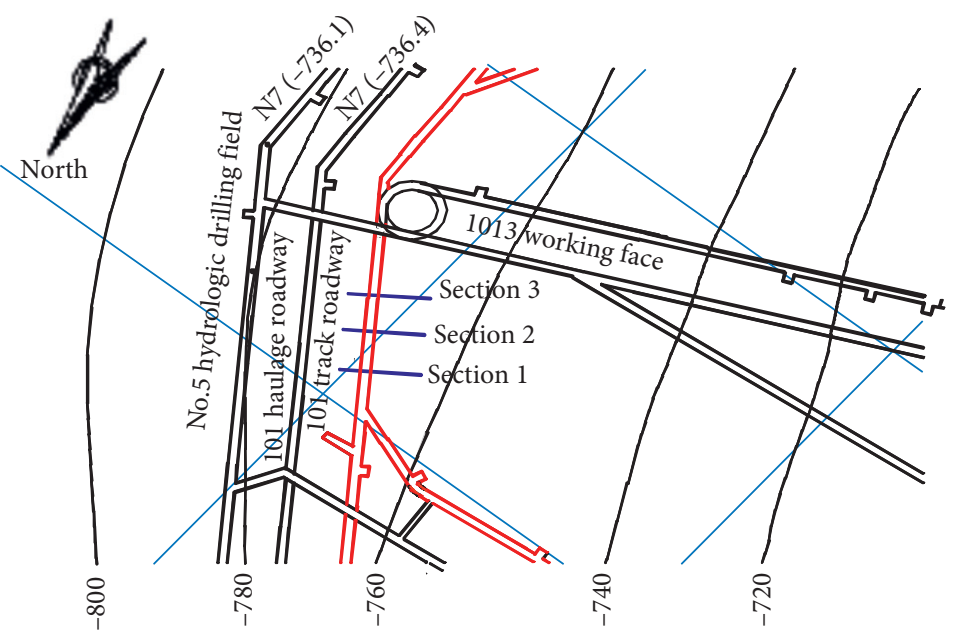

(a)

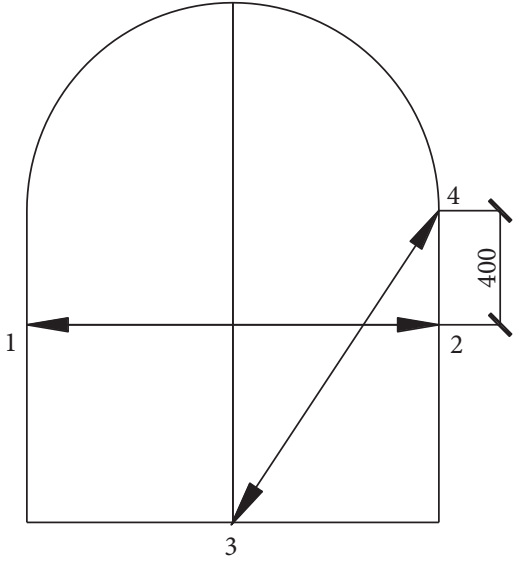

(b)

FIgURE 14: Schematic diagram of detection section site layout.

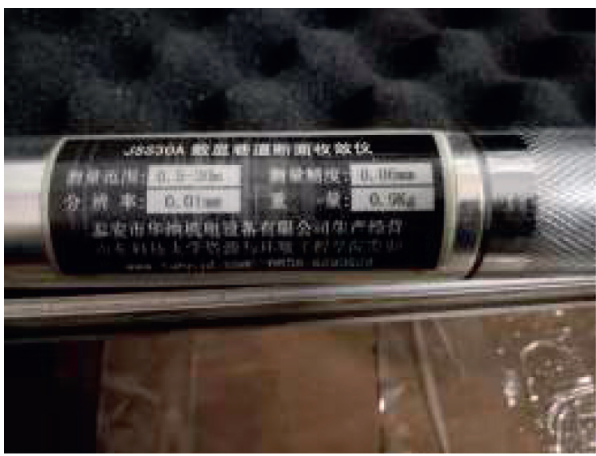

(a)

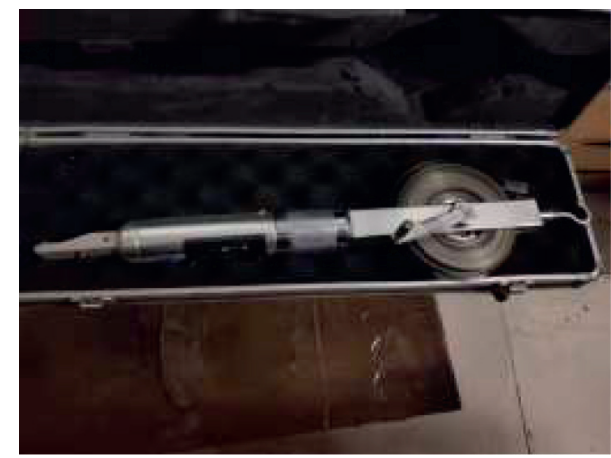

(b)

FIGURE 15: JSS30A digital display roadway section convergence instrument. 


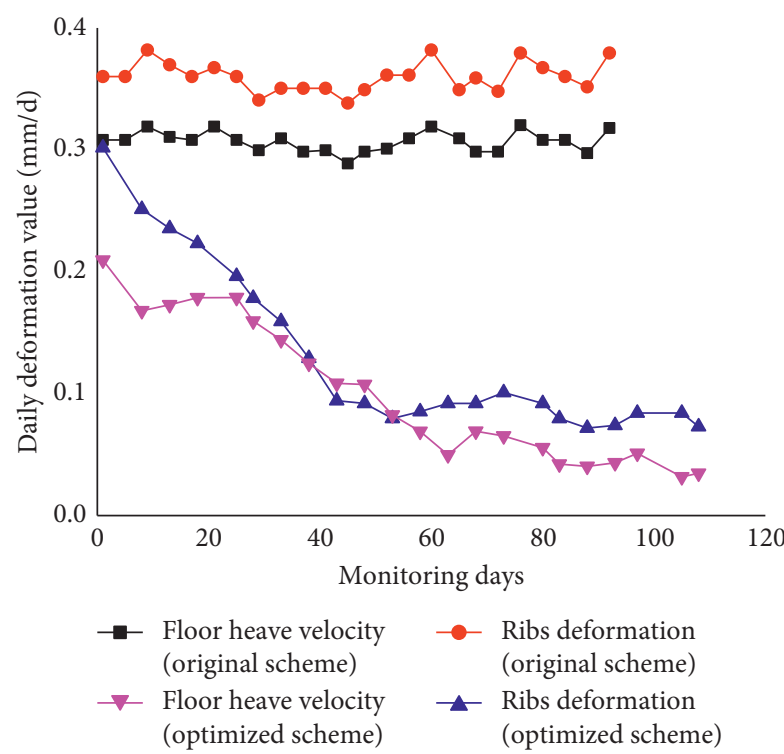

Figure 16: Comparison of approaching velocity of roadway sides and floor heave velocity before and after treatment.

reduction of 4.14 times, which was only $19.4 \%$ of that before reinforcement. The floor heave velocity decreased from $0.32 \mathrm{~mm} /$ day to $0.03 \mathrm{~mm} /$ day with a reduction of 9.7 times, which was only $9.38 \%$ of that before reinforcement. Furthermore, the deformation velocity of the roadway sides and floor heave is still decreasing, so the reinforcement effect is very significant.

\section{Conclusions}

(1) According to the loading and unloading properties of surrounding rock, a new concept of internal and external bearing structure of the surrounding rock is put forward, and it is pointed out that in addition to the ground stress and properties of surrounding rock, the shape and size of the internal and external bearing structures of surrounding rock also play a key role in controlling the stability of surrounding rock

(2) The field practice shows that the rock mass of roadway floor in many coal mines is water-immersed and softened due to the accumulation of a large amount of water, which results in a great decrease in rock strength, and the strength failure or unstable creep failure of the external nonimmersed rock mass continues to occur due to the decrease of internal supporting force, resulting in the continuous expansion of the floor loose zone. Therefore, the vertical size of the actual loose zone is much larger than the transverse size, and the whole loose zone is approximately elliptical. In addition, the range of the actual floor loose ring is much larger than the results of previous computer numerical simulations

(3) The deformation control mechanism and key control point of the surrounding rock of deep soft roadway were revealed based on the mechanics' principle, and a support technology suitable for deep soft roadway under the condition of long-term water immersion on the floor was proposed, which used double-row anchor cables to strengthen the key control points of the roadway sides so that the deformation of the roadway floor heave and the roadway sides can be effectively controlled. The field measurement results show that this technology can maintain the longterm stability of the surrounding rock of deep soft rock roadway and provide a guarantee for the safe production of coal mine

\section{Data Availability}

The data used to support the findings of this study are included within the article.

\section{Conflicts of Interest}

The authors declare no conflicts of interest.

\section{Acknowledgments}

This study was supported by the National Natural Science Foundation of China (No. 51904012), Open Fund of State Key Laboratory of Mining Response and Disaster Prevention and Control in Deep Coal Mine (SKLMRDPC19KF02), Natural Science Foundation of Education Department of Anhui Province (KJ2019A0099), Funded Project of Scientific Research Activities for Postdoctoral Researchers of Anhui Province (2018B268), and Key Project of Science Foundation for Young Teachers of Anhui University of Science and Technology (QN2018104).

\section{References}

[1] X. Q. Wang, J. Q. Kan, and J. K. Jiao, "Mechanism of floor heave in the roadway with high stress and soft rock and its control practice," Journal of Mining \&Safety Engineering, vol. 34, no. 2, pp. 214-220, 2017, in Chinese.

[2] W. J. Wang and H. Wan, "Mechanical characteristics analysis of fully grouted GFRP rock bolts in highly stressed soft rock tunnels," Journal of Mining \&Safety Engineering, vol. 36, no. 3, pp. 482-490, 2019, in Chinese.

[3] L. Sun, H. Wu, B. Yang, and Q. Li, "Support failure of a highstress soft-rock roadway in deep coal mine and the equalized yielding support technology: a case study," International Journal of Coal Science \& Technology, vol. 2, no. 4, pp. 279286, 2015.

[4] R. Li, Q. Wang, B. Jiang et al., "Failure of bolt support and experimental study on the parameters of bolt-grouting for supporting the roadways in deep coal seam," Engineering Failure Analysis, vol. 80, no. 10, pp. 218-233, 2017.

[5] F. Li, D. Stead, and H. Kang, "Simulation of roof shear failure in coal mine roadways using an innovative UDEC Trigon approach," Computers and Geotechnics, vol. 61, pp. 33-41, 2014.

[6] W. R. Liu, J. K. Liu, and C. Zhu, "Multi-scale effect of acoustic emission characteristics of 3D rock damage," Arabian Journal of Geosciences, vol. 12, no. 668, pp. 1-13, 2019.

[7] T. H. Sheng, T. S. Hao, W. Chen et al., "Mechanical analysis of a vertical-wall, semicircular-arch roadway and a repair 
technique using double-shell support," Environmental Earth Sciences, vol. 77, no. 509, pp. 1-18, 2018.

[8] Q. Wang, R. Pan, S. C. Li et al., "The control effect of surrounding rock with different combinations of the bolt anchoring lengths and pre-tightening forces in underground engineering," Environmental Earth Sciences, vol. 77, no. 501, pp. 1-14, 2018.

[9] B. Wang, W. J. Wang, F. J. Zhao et al., "Study of bolt anchoring effect based on self-bearing characteristics of roadway surrounding rock," Rock and Soil Mechanics, vol. 35, no. 7, pp. 1965-1972, 2014, in Chinese.

[10] C. J. Hou, "Effective approach for surrounding rock control in deep roadway," Journal of China University of Mining \& Technology, vol. 46, no. 3, pp. 467-547, 2017, in Chinese.

[11] J. H. Zhao, A. G. Li, and C. G. Zhang, "Self-carrying capacity of surrounding rock for a circular tunnel based on elasticbrittle-plastic model," China Journal of Highway and Transport, vol. 27, no. 4, pp. 85-90, 2014, in Chinese.

[12] A. J. Das, P. K. Mandal, R. Bhattacherjee et al., "Effect of fault on the stability of workings underground extraction of coal," Nexgen Technologies for Mining and Fuel Industries, vol. 1, pp. 155-166, 2017.

[13] J. H. Zhang, Y. Jiang, Y. Q. Fan et al., "Instability mechanism of surrounding rock of weakly cemented soft strata in shallow coal seam of West China," Electronic Journal of Geotechnical Engineering, vol. 22, no. 1, pp. 321-330, 2017.

[14] Y. L. Xu, K. R. Pan, and H. Zhang, "Investigation of key techniques on floor roadway support under the impacts of superimposed mining: theoretical analysis and field study," Environmental Earth Sciences, vol. 78, no. 436, pp. 1-14, 2019.

[15] H. Kang, "Support technologies for deep and complex roadways in underground coal mines: a review," International Journal of Coal Science \& Technology, vol. 1, no. 3, pp. 261-277, 2014.

[16] J. X. Tang, Y. L. Wang, G. J. Shu et al., "Mechanism and control of failure for surrounding rock in highly stressed "three soft" coal seam mining roadway," Journal of Mining «Safety Engineering, vol. 35, no. 3, pp. 449-456, 2018, in Chinese.

[17] Q. X. Huang and C. Zheng, "Theory of self-stable ring in roadway support," Rock and Soil Mechanics, vol. 37, no. 5, pp. 1231-1236, 2016, in Chinese.

[18] Y. Chen, Q. Meng, G. Xu, H. Wu, and G. Zhang, "Boltgrouting combined support technology in deep soft rock roadway," International Journal of Mining Science and Technology, vol. 26, no. 5, pp. 777-785, 2016.

[19] Z. Z. Wu, "Analysis of the large deformation mechanism of soft rock tunnel in great fault area and construction controls," Electronic Journal of Geotechnical Engineering, vol. 20, no. 25, pp. 12185-12193, 2015.

[20] C. Yuan, W. J. Wang, T. Feng et al., "Research on control principles of surrounding rocks of roadway based on expansion of plastic zone," Journal of Mining \& Safety Engineering, vol. 34, no. 6, pp. 1051-1059, 2017, in Chinese.

[21] H. P. Kang, J. Lin, and M. J. Fan, "Investigation on support pattern of a coal mine roadway within soft rocks-a case study," International Journal of Coal Geology, vol. 140, pp. 31-40, 2015.

[22] W. Jing, Theoretical and Experimental Research on Deformation Partition of Circular Roadway, Ph.D. Dissertation, in Chinese, Anhui University of Science \& Technology, Huainan, China, 2017.
[23] F. T. Dong, The Supporting Theory Based on Loose Zone and Its Application Technology, China Coal Industry Publishing House, Beijing, China, 2001.

[24] L. Gao, Mine Rock Mechanics, China Machine Press, Beijing, China, 1987.

[25] M. Tian, L. Han, Q. Meng, Y. Jin, and L. Meng, "In situ investigation of the excavation-loose zone in surrounding rocks from mining complex coal seams," Journal of Applied Geophysics, vol. 168, pp. 90-100, 2019.

[26] H. Jin, S. Cao, Y. Li et al., "Assessment of excavation broken zone around gateways under various geological conditions: a case study in Sichuan Province, China," Minerals, vol. 6, no. 3, p. 72, 2016.

[27] Y. L. Fan, Deformation Instability Mechanism and Supporting Technology of Large-Section Coal Roadway with Layered Roof in Zhaozhuang Coal Mine, Ph.D. Dissertation, in Chinese, China University of Mining and Technology, Beijing, China, 2017.

[28] C. L. Dym and I. H. Shames, Solid Mechanics, Springer, New York, NY, USA, 2013.

[29] K. D. Hjelmstad, Fundamentals of Structural Mechanics, Springer, Boston, MA, USA, 2005. 